\title{
Further characterization of OT4 Mesozoic reference zircon
}

\author{
K. HORIE ${ }^{1,2 *}$, M. TAKEHARA ${ }^{1}$, T. HOKADA $^{1,2}$
}

${ }^{1}$ National Institute of Polar Research, 10-3, Midori-cho, Tachikawa 190-8518, Japan (*correspondence: horie.kenji@nipr.ac.jp)

2 The Graduate University for Advanced Studies, SOKENDAI, Midori-cho 10-3, Tachikawa, 190-8518, Japan

Zircon is one of common refractory accessory minerals occurring in a wide range of crustal rocks, and is not only the most useful mineral for geochronology based on the radioactive decay of $\mathrm{U}$ to $\mathrm{Pb}$, but also one of the most important geochemical tracers in terms of its $\mathrm{Hf}$ and $\mathrm{O}$ isotopes and trace element compositions. U-Pb dating using microbeam technique such as SIMS and LA-ICP-MS requires suitable reference materials. It is desirable to the reference materials have radiation damage same as that of the target, namely similar age and actinoid concetration. The reference zircons with Mesozoic age are not common, which gets in the way of precise and accurate dating of Mesozoic zircons. In this presentation, we report new precise $\mathrm{U}-\mathrm{Pb}$ age obtained by ID-TIMS, trace element concentration, and isotope data of lithium and oxygen of the OT4 zircon which is the Mesozoic reference zircon for $\mathrm{U}-\mathrm{Pb}$ dating [1].

The U-Pb weighted mean age of the OT4 zircon is $191.464 \pm 0.034 \mathrm{Ma}(\mathrm{n}=5$, MSWD $=0.83)$, which is consistent with the previous report. The preliminary oxygen isotopic ratio in the OT4 zircon obtained by SHRIMP-IIe/AMC is $6.09 \pm 0.07 \%$ o $(n=35)$, which indicates that source melt of the OT4 zircon was affected by sediments. Ti concentrations of the OT4 zircon are from 3.4 to $17.3 \mathrm{ppm}$ and the average is $6.8 \pm 3.1 \mathrm{ppm}(\mathrm{SD})$. Assuming Ti activity of 0.7 , Ti-in-zircon temperatures are $681-827^{\circ} \mathrm{C}$ and the average is $733 \pm 34^{\circ} \mathrm{C}$ (SD), and are consistent with the $\mathrm{Zr}$ saturation temperature $\left(728^{\circ} \mathrm{C}\right)$ calculated from bulk rock composition. The REE patterns are characterized by strongly positive $\mathrm{Ce}$ anomalies, and negative $\mathrm{Eu}$ anomalies. Li concentration of the OT4 zircon is higher that those of TEMORA2 and 91500. Further information such as $\mathrm{Li}$ isotopic ratio and other trace element concentrations will be demonstrated.

[1] Horie et al. (2013) Island Arc 22, 292-305. 